\title{
O Brinquedo de Pré-Escolares: Um Espaço de Ressignificação Cultural ${ }^{1}$
}

\author{
Luciane De Conti ${ }^{2}$ \\ Universidade de Santa Cruz do Sul \\ Tania Mara Sperb \\ Universidade Federal do Rio Grande do Sul
}

\begin{abstract}
RESUMO - Este artigo analisa a construção do significado social do brincar em um grupo de crianças pré-escolares, cinco meninos e cinco meninas. Para atingir este objetivo, mães e a professora destas crianças foram entrevistadas para definir suas concepções sobre o brincar. As atividades de brincar das crianças selecionadas foram filmadas em casa e na escola, durante vinte minutos em cada contexto, visando observar como elas organizam esta atividade. A análise de conteúdo das entrevistas e a categorização do brincar demonstram que esta atividade é estruturada distintamente conforme o gênero da criança e o contexto em que ela ocorre. A microanálise das atividades de brincar de quatro crianças explicita que estas ativamente reelaboram os espaços de brincar, criando novos cenários para suas brincadeiras e inventando novas funções para os objetos disponíveis em sua cultura. Ao fazer isto, redefinem os papéis sexuais estereotipados como masculino, feminino ou indiferenciado pelo contexto sociocultural.
\end{abstract}

Palavras-chave: sociocultural; brinquedo; cultura.

\section{Preschoolers' Play: A Space for Cultural Re-Signification}

\begin{abstract}
This article analyses the construction of the social meaning of play in a particular preschool group of children, five boys and five girls. To do that children's mothers and teachers were interviewed to define their conceptions about play. After, children were filmed for twenty minutes while playing, both at home and in school, in order to analise how children organize their activities. Content analysis of interviews and the categorization of children's play show that play activities are structured differently by gender and the context where play occurs. The microanalysis of the videotapes of four children's play explicit that they actively reconstruct play, building news scenarios, and inventing new functions for existing objects in the culture. Children do that by redifining sexual roles stereotyped as masculine, feminine and undiferentiated by sociocultural context.
\end{abstract}

Key words: sociocultural; play; culture.

As crianças em todas as épocas têm passado grande parte do seu tempo brincando. A importância desta atividade para o desenvolvimento infantil é consenso entre os teóri$\cos$; no entanto, o mesmo não ocorre com o conceito de brincar, cuja definição científica permanece imprecisa até hoje.

Uma das primeiras teorias sobre o brincar infantil, por exemplo, surgiu no século XVIII e entendia esta atividade como o produto de uma energia excedente (Groos, 1896/ 1976). Já os estudiosos que dominaram as teorias do brincar na primeira metade do século XX, como Piaget (1945/1978) e Vygotsky (1933/1989), definem o brincar a partir da sua relação com o desenvolvimento psicológico mais amplo. Posteriormente, temos teóricos como Berlyne (1963) que expli-

1 Este trabalho é uma síntese da dissertação de Mestrado apresentada no Curso de Pós-Graduação em Psicologia do Desenvolvimento da UFRGS, sob a orientação de Tania Mara Sperb; e contou com o apoio financeiro da CAPES. As autoras agradecem a Marjorie Loh pelo fundamental auxílio na coleta e codificação dos dados.

2 Endereço: Departamento de Psicologia. Av. Independência, 2293 Campus Universitário - Santa Cruz do Sul-RS. CEP: 96815-900. Email: luciane@dpsico.unisc.br ca o brincar como um comportamento intrinsicamente motivado; e Bruner (1972/1976) que postula o brincar como uma atividade que deve facilitar a aprendizagem e/ou a prática de comportamentos específicos.

Um outro enfoque teórico (Schwartzman,1978) enfatiza as relações entre texto e contexto no brincar infantil. Dele derivam os estudos preocupados em estabelecer o papel dos diferentes contextos na estruturação do brincar. Schwartzman talvez tenha sido uma das primeiras investigadoras a chamar a atenção para este fato, salientando que é importante interpretar os textos do brincar levando em consideração os contextos sociais específicos em que eles se desenvolvem. A autora enfatiza que não podemos separar artificialmente o texto e o contexto em que o brincar acontece, mas que devemos relacionar esta atividade ao valor e ao lugar que lhe são determinados pela cultura na qual ela ocorre, para desse quadro derivarmos o significado do brincar.

Como aponta Pedrosa (1996), a criança desde seu nascimento integra-se num mundo de significados construídos historicamente. E através da interação com seus parceiros sociais, envolve-se no processo de significação dela própria 
e de objetos, eventos e situações outras, construindo e reconstruindo ativamente novos e velhos significados.

Segundo Shweder (1991), cognição e cultura têm sido vistas, muitas vezes, como processos separados. As teorias desenvolvidas na área da Psicologia Cultural, por sua vez, entendem estes processos como interdependentes. Lucariello (1995) salienta que a Psicologia Cultural deveria ter como unidade de análise as realidades ou estruturas culturalmente compartilhadas através das quais as pessoas interpretam os ambientes; ou seja, coloca que é necessário articular o papel da pessoa, que é quem interpreta a realidade através de categorias ou estruturas socialmente e culturalmente compartilhadas, na análise de qualquer fenômeno.

Para Wertsch (1991) é o enfoque sociocultural da mente que deve explicar e descrever a ação humana. Esta ação é mediada, porque ela é executada pelo indivíduo ou grupo, que emprega um código cultural, o qual promove a ligação entre o setting sociocultural e o funcionamento mental. A ação humana provém então de um contexto em que indivíduo e sociedade são compreendidos como inter-relacionados (Wertsch, 1995). Esse autor enfatiza que uma situação, evento ou objeto tem muitas interpretações possíveis e que o diálogo serve tanto para impor uma interpretação particular quanto para criar uma realidade social compartilhada temporalmente.

A esta visão, Valsiner (1988) acrescenta que o desenvolvimento da criança ocorre em ambientes que são fisicamente estruturados de acordo com os sistemas de significado cultural das pessoas que habitam estes ambientes. Cultura, na concepção do autor, refere-se à organização estrutural de normas sociais, rituais, regras de conduta e sistemas de significado compartilhados pelas pessoas que pertencem a um certo grupo etnicamente homogêneo. Há duas facetas da cultura que são indistinguíveis: a cultura como entidade coletiva (significados compartilhados coletivamente) e a cultura como entidade pessoal (versão pessoal). A primeira é aprendida pela criança no contexto das experiências vivenciadas em seus ambientes, mais que meramente nos settings onde adultos explicitamente ensinam a criança. Isto significa que os pais organizam os ambientes de vida de seus filhos de tal forma que promovem a transmissão cultural de acordo com suas significações.

A compreensão e a percepção que o adulto tem sobre a atividade de brincar da criança são guiadas por seus sistemas de significado cultural. A criança, por sua vez, como salientam Valsiner (1988) e Winegar (1988), transcende a cultura de seus pais no processo de apreendê-la, reconstruindo as experiências adquiridas em seus espaços físicos, inventando cenários novos para exercer o seu faz-de-conta e criando novas funções para os objetos que lhe são oferecidos pelo grupo a que pertence. Ao fazer isto, ela externaliza sua compreensão dos eventos sociais e, ao mesmo tempo, reconstrói o significado social desta atividade.

O faz-de-conta, então, ocorre dentro de um ambiente culturalmente organizado em que a criança se desenvolve e o qual providencia os objetos que ela usará nesta atividade. O brincar é uma atividade prática, na qual as crianças cons- troem e transformam seu mundo, conjuntamente, renegociando e redefinindo a realidade. Assim, o brincar compreende uma construção da realidade, a produção de um mundo e a transformação do tempo e do lugar em que ele pode acontecer. A participação da criança nesta atividade requer um senso de realidade compartilhado do que é verdadeiro ou falso, certo ou errado (Packer, 1994). O papel ativo da criança na transmissão cultural garante que a cultura de sua geração vá além daquela de seus pais, pois as mensagens culturais emitidas pelos adultos à criança são ativamente assimiladas por ela em suas estruturas de conhecimento, de modos novos.

Considerando, então, em primeiro lugar, que os ambientes em que ocorre a atividade de brincar da criança são estruturados fisicamente de acordo com as crenças das pessoas responsáveis por esta atividade; em segundo lugar, que a criança ocupa um papel ativo na organização de suas atividades, construindo a sua versão pessoal dos eventos sociais, que lhe são transmitidos pelos membros mais competentes de sua cultura; em terceiro lugar, que a criança externaliza esta compreensão através da ação e, em quarto lugar, que cada classe social, como aponta Kohn (conforme citado por Tudge, Putnam \& Sidden, 1993), apresenta um sistema de significado cultural próprio, é que este estudo propôs-se a investigar a construção do significado social do brincar por crianças pré-escolares pertencentes a um grupo cultural em particular, definido neste estudo em termos de classe social. Para atingir estes objetivos, levantaram-se as seguintes questões norteadoras:

1) Quais os sistemas de significado cultural das mães e da professora das crianças observadas que definem o brincar infantil?

2) Que tipos de brincadeiras e de objetos observam-se na atividade de brincar destas crianças? Quais os temas construídos em suas brincadeiras imaginativas?

3) Existem diferenças e similaridades nos tipos de brincadeiras, de objetos e de temas presentes nas atividades de brincar das crianças investigadas entre os contextos de casa e da escola?

4) Qual a versão pessoal das crianças investigadas acerca do fenômeno brinquedo?

\section{Método}

Nesse estudo, utilizou-se uma metodologia qualitativa. Nesta perspectiva, a investigação ocorreu em dois níveis, relacionados entre si. No primeiro nível buscou-se definir o significado atribuído ao brincar por mães e por professores, configurando-se-lhes o contexto sociocultural de sua ocorrência. No segundo nível, objetivou-se examinar, num primeiro momento, a atividade de brincar das crianças-foco em seus contextos de casa e da escola. O método de observação de criança-foco descrito por Tudge e cols. (1993) visa detectar as atividades da mesma criança em diferentes settings e em diversas ocasiões, relevantes para os objetivos da pesquisa. Em um segundo momento, procurou-se entender como a criança, sujeito da ação, lida com as crenças e os valores dados pelo grupo cultural a que pertence, dando sentido a eles. 


\section{Participantes e contextos da pesquisa}

Participaram desta pesquisa dez crianças (cinco meninos e cinco meninas), com idade entre cinco anos e seis anos e nove meses, que frequientavam o jardim de infância, no turno da tarde, suas mães e a professora da turma. A faixa de idade das mães concentrou-se entre 25 e 35 anos. A grande maioria estudou da quinta a oitava série, trabalhava em serviços gerais como costureira, contabilista, vendedora de roupas (autonôma) e era natural do interior do Estado. Os dados foram coletados na casa das crianças selecionadas e em uma escola municipal infantil de Porto Alegre, que atende crianças de zero a sete anos. Em torno de $66 \%$ da amostra reside em área invadida cuja população é composta em sua maioria por operários e trabalhadores informais. As atividades desenvolvidas com as crianças na escola são letramento, higiene, alimentação, brinquedo livre no pátio e na sala-de-aula.

\section{Material e procedimento}

A turma foi indicada pela diretora da escola com a aquiescência da professora. Realizou-se um período de familiarização com a rotina escolar durante um mês e quinze dias, através do qual se conseguiu conhecer as crianças em suas rotinas diárias, a filosofia de trabalho da instituição e da professora da turma em particular. Também conversas com as crianças esclareceram a presença da pesquisadora no local. A seleção das crianças-foco levou em consideração o local de moradia das mesmas, a participação dos pais na escola e a aprovação dos mesmos para que seus filhos fossem filmados. As filmagens foram iniciadas somente após um período inicial de familiarização das crianças com a câmera. Em paralelo, as mães e a professora das crianças-foco foram entrevistadas.

a) Entrevistas: foi realizada uma entrevista com as mães de cada criança selecionada e uma com a professora da turma que estas crianças freqüentavam. A entrevista com as mães ocorreu em suas casas, em dia e hora previamente marcados, e abrangeu temas como: dados demográficos (idade, nível educacional, profissão, tamanho da família, de quem é a casa, quanto tempo vivem no local); rotina familiar (quem cuida da criança, atividades cotidianas); desenvolvimento da criança (o que é desenvolvimento, se a criança está se desenvolvendo dentro do esperado) e fenômeno brinquedo (o que é brincar, a importância desta atividade para o desenvolvimento infantil e porquê, formas utilizadas para estimular o brincar das crianças, rotina do brincar das crianças: onde, duração, com quem, tipos de brincadeira, objetos utilizados; a relevância do brincar na escola). A entrevista com a professora foi realizada na escola e compreendeu dados pessoais, filosofia de trabalho, relação existente entre educação e brincar e percepções acerca do brinquedo. As entrevistas foram gravadas e, em um segundo momento, transcritas para posterior análise de conteúdo.

b) Sessões de observação: foram realizadas durante o período de brinquedo livre das crianças, em dias e horas diferentes, durante 20 minutos em cada contexto, perfa- zendo um total de 40 minutos. Na escola, a filmagem foi feita durante o recreio livre, dentro e fora da sala-deaula, incluindo na filmagem todas as pessoas que estavam com a criança no momento. Em casa, foi realizada uma sessão de observação, sendo que a auxiliar de pesquisa filmou a criança enquanto a pesquisadora entrevistava a mãe da mesma. Neste contexto, filmou-se o brincar da criança sozinha e/ou com quem participasse com ela desta atividade, onde quer que esta ocorresse: em qualquer cômodo da casa, no pátio. Utilizou-se uma câmera móvel para as filmagens, que eram interrompidas toda vez que a atividade de brincar cessava (por exemplo, quando o recreio encerrava ou a criança parava o brincar para ir ao banheiro), ou que a criança-foco saía do alcance da câmera (por exemplo, deslocava-se rapidamente para outra peça da casa ou do pátio). Os vídeos foram cronometrados a partir da primeira filmagem da atividade de brincar de cada criança e, posteriormente, as verbalizações das crianças-foco e de seus parceiros nas atividades de brincar foram transcritas para fins de codificação.

c) Objetos de brincar: foram utilizados todos os objetos disponíveis na escola (por exemplo, jogos de números e de letras, quebra-cabeças, lego, marionetes, fantoches, sacos de areia, bonecas, louças, carrinhos, espadas, robôs, cordas de pular, bola, balanço, pneus, tóneis, baldes, pás, violão, tambor e pandeiro) e na casa da criança como: instrumentos musicais, sacos de lixo, cubos de papel higiênico, panos, bacias, água, bichos de pelúcia, bonecas e acessórios, carrinhos, aviões, binóculos e bicicletas.

\section{Resultados e Discussão}

Os resultados foram analisados em três etapas, interdependentes.

\section{Primeira etapa: Percepções das mães e da professora sobre a atividade de brincar das crianças-foco}

Nesta etapa, delimitaram-se categorias a partir do conteúdo verbal expresso pelas mães e pela professora em suas entrevistas orais. As categorias elaboradas englobam, entre outros aspectos, o conceito de brincar, sua importância para o desenvolvimento, os tipos de brincadeiras e de objetos citados pelas mães e pela professora das crianças-foco como característicos da atividade de brincar de seus filhos e alunos, respectivamente.

O brincar é considerado pela maioria das mães entrevistadas como uma atividade típica da infância e uma atividade em que ocorre a manipulação de objetos. A importância da atividade de brincar para o desenvolvimento da criança é relacionada ao desenvolvimento afetivo, cognitivo e ao da criatividade. Em suas percepções da importância da atividade de brincar para o desenvolvimento da criança, as mães explicitam, principalmente, os conceitos formulados pelos teóricos como Bruner (1972/1976) de que o brincar é uma prática do comportamento adulto; como Freud (1908/1976) de que no brinquedo a criança realiza o desejo de ser grande 
e adulto e como Piaget (1945/1978) e Vygotsky (1933/1989), que relacionam o brincar da criança com o desenvolvimento cognitivo.

As mães citam em suas entrevistas tipos de brincadeiras e de objetos distintos para o brincar de seus filhos, dependendo do gênero dos mesmos. Por exemplo, meninos utilizam em suas brincadeiras objetos como: corda, bolas, bolitas, Cavaleiros do Zodíaco, carrinhos, espadas, revólver, pregos e martelo; enquanto as meninas costumam brincar com: bonecas, xícaras, roupas de boneca, utensílios para maquilagem, artefatos de casa. As brincadeiras masculinas, segundo as mães, são: brigar, Superman, Batman, futebol, dirigir, polícia-ladrão, quartel, posto de gasolina; e as femininas caracterizam-se por: casinha, dançar, cantar, Xuxa, bebê, roda.

As mães apontam também alguns objetos de brincar comuns tanto a seus filhos homens quanto a suas filhas mulheres, como: jogos de montar, Lego, bicicleta, material escolar, animais; e algumas brincadeiras como: assistir televisão, correr, escolinha, pega-pega, andar de bicicleta, patacega. Portanto, dependendo do gênero de seus filhos, as mães deste grupo descreveram brincadeiras e tipos de objetos distintos, estabelecendo normas específicas que determinam os objetos a serem utilizados por uns e não por outros e as brincadeiras típicas de cada gênero.

Vários estudos (Farver \& Wimbarti, 1995; Gaskins \& Goncü, 1992; Gralinski \& Kopp, 1993) demonstram que os pais organizam os ambientes em que suas crianças brincam de acordo com as suas crenças e com os seus valores acerca desta atividade. A compreensão da criança sobre os eventos sociais, como aponta Winegar (1988), emerge da sua interação com seus parceiros nos contextos cotidianos. Valsiner (1989) coloca que o mundo adulto dá para a criança uma variedade de objetos e de modos de interagir que são semioticamente marcados pelos papéis sexuais estereotipados como masculino, feminino ou indiferenciado. A atividade de brincar é um dos settings onde a criança constrói estes papéis, de acordo com as sugestões sociais determinadas pela cultura coletiva. As mães entrevistadas provavelmente canalizam as ações, as percepções e as representações da criança em direção a um funcionamento social aprovado de acordo com suas crenças e valores. Porém, a criança tem um papel ativo neste processo, redefinindo os papéis sexuais conforme sua versão acerca dos valores e das crenças transmitidas. Em decorrência desta suposição, especifica-se ainda mais a questão 1 formulada no início desse estudo, desdobrando-a em dois aspectos: meninos e meninas organizam suas brincadeiras distintamente? Utilizam objetos diferentes ao brincar?

Já para a professora, as crianças costumam brincar de: correr e pular, casinha, cadeia e construções; e utilizam nestas brincadeiras: quebra-cabeça, blocos lógicos, jogos de plástico, carrinhos, blocos de madeira, pneus e boneca. Os tipos de objetos e de brincadeiras não foram categorizados pela professora de acordo com o gênero da criança, mas em função dos desejos e das necessidades intrínsecas da mesma. Isto denota que os sistemas de significado cultural das mães e da professora diferem entre si. Posto que a forma particular que a relação entre casa e escola ocupa no desenvolvimento da criança depende da convergência e da divergência nos objetivos das duas instituições de socialização (Valsiner, 1989), a terceira questão formulada no início do estudo impõe-se como interessante: existem diferenças e similaridades nos tipos de brincadeiras, de objetos e de temas presentes nas atividades de brincar das crianças-foco entre os contextos de casa e da escola?

\section{Segunda etapa: Descrição e comparação entre as atividades de brincar das dez crianças-foco de acordo com o gênero e o contexto em que a atividade ocorria}

A segunda etapa desta pesquisa constituiu-se pela codificação das sessões de observação. As atividades de brincar foram categorizadas de acordo com os tipos de brincadeiras, os tipos de objetos utilizados nestas brincadeiras e os temas criados pelas crianças em suas brincadeiras de jogos de papéis. As brincadeiras foram agrupadas ainda de acordo com o gênero da criança e os contextos em que a atividade ocorria, casa e escola. Descreveu-se genericamente o brincar das crianças-foco e se verificou as diferenças e similaridades entre meninos e meninas e entre os contextos.

Para os tipos de brincadeiras, utilizou-se uma adaptação da categorização elaborada por Tudge, Sidden e Putnam (1990), a qual compreende jogos de papéis e brincadeiras exploratórias. A categoria jogos de papéis refere-se tanto àquelas atividades de brincar em que a criança assume o papel de uma coisa ou criatura, denominada faz-de-conta genérico (por exemplo, brincar de monstro); como àquelas que envolvem cenas em que a criança adota papéis típicos de outras pessoas e representa situações humanas cotidianas, definida como imitação de papéis adultos (por exemplo, brincar de papai e mamãe, mãe e filho, professor e aluno). Em um segundo momento, as brincadeiras jogos de papéis foram classificadas ainda de acordo com os temas e com os tipos de objetos utilizados nestas brincadeiras. Os temas desenvolvidos pelas crianças-foco foram: tarefas domésticas (limpar a casa, amamentar e dar banho no filho, cozinhar, tomar banho); relações familiares e extra-familiares, que envolvem todas as brincadeiras que centraram-se nas relações em si (família, vizinhança, namoro); atividades cotidianas (passeio, natação, desfile, tiroteio); fantásticos (Superman, Chapolin, Cavalheiros do Zodíaco); e serviços gerais, que englobam prestação de serviços (polícia, posto de gasolina, transporte). Os objetos utilizados pelas crianças em suas brincadeiras foram também categorizados com base na classificação de brinquedos proposta por Michelet (1992): objetos para o desenvolvimento afetivo (bonecas e acessórios como berços, maquilagem, roupas, panelinhas, bijouterias, sapatos de salto, bolsas, aparelhos que imitam rádios e televisão, aviões, binóculos, máscaras, ferrorama, caminhões, carrinhos, robôs); objetos para atividades físicas (bicicletas, raquetes, bola, gangorra, pneus, tóneis); para atividades intelectuais (jogos, quebra-cabeça); sem uso específico (sucatas, animais, areia, folhas de árvore) e para atividades sensório-motoras (balde, pá, peças de encaixar e de empilhar). 
A categoria brincadeiras exploratórias envolve todas as brincadeiras em que a criança não assume o papel de outra pessoa, coisa ou criatura e engloba as seguintes subcategorias de objetos: 1) orientados para a criança: qualquer objeto manufaturado ou preparado para o uso específico da criança, sem fins acadêmicos claros (na escola, por exemplo, os pneus foram colocados no pátio para a diversão das crianças); 2) orientados para o adulto: qualquer objeto do mundo adulto que não foi elaborado para o uso da criança, mas que esta utiliza em suas brincadeiras (por exemplo, sacos de lixo cheios de sucatas, talheres); 3 ) naturais: qualquer objeto que faz parte do mundo natural como água, areia, folhas de árvore ou o próprio corpo da criança (mãos, voz, braços); 4) acadêmicos: todos objetos manufaturados com fins acadêmicos claros (por exemplo, quebra-cabeças, legos).

As tabelas 1 e 2 descrevem os tipos de objetos utilizados por meninos e meninas em suas brincadeiras, nos contextos de casa e da escola. As tabelas 3 e 4 ilustram os tipos de temas construídos pelas crianças-foco nas brincadeiras de jogos de papéis, nos distintos contextos.

A análise comparativa entre as tabelas 1 e 2 mostra que há diferenças no brincar de meninos e de meninas no contexto de casa; por exemplo, meninas costumam brincar de imitação de papéis adultos ao contrário dos meninos, que brincam somente de faz-de-conta genérico. Também, o uso

Tabela 1. Quantidade de meninos de acordo com o tipo de objeto usado e o tipo de brincadeira observada nos contextos de casa (C) e da escola (E) ${ }^{4}$

\begin{tabular}{lccccccccccc}
\hline & \multicolumn{8}{c}{ Tipos de Objetos } \\
\cline { 2 - 11 } Tipos de Brincadeiras & \multicolumn{1}{c}{ AI } & \multicolumn{1}{c}{ SUE } & \multicolumn{1}{c}{ DA } & \multicolumn{1}{c}{ AF } & \multicolumn{2}{c}{ ASM } \\
\cline { 2 - 11 } & & C & E & C & E & C & E & C & E & C & E \\
\hline Jogos de Papéis & FCG & - & 1 & - & - & 3 & - & 1 & - & 4 & 1 \\
& IPA & - & - & - & 3 & - & - & - & - & - & 2 \\
\hline Exploratórias com & OC & 1 & - & 1 & - & 4 & - & 3 & 5 & 4 & 4 \\
Objetos & OA & - & 1 & 1 & 1 & - & - & - & 2 & - & - \\
& N & - & - & 3 & 3 & - & - & - & - & - & 2 \\
& A & - & 1 & - & - & - & - & - & - & - & 1 \\
\hline Total & & 1 & 3 & 5 & 7 & 7 & 0 & 4 & 7 & 8 & 10 \\
\hline
\end{tabular}

Tabela 2. Quantidade de meninas de acordo com o tipo de objeto usado e o tipo de brincadeira observada nos contextos de casa (C) e da escola (E) ${ }^{4}$

\begin{tabular}{|c|c|c|c|c|c|c|c|c|c|c|c|}
\hline \multirow{2}{*}{\multicolumn{2}{|c|}{ Tipos de Brincadeiras }} & \multicolumn{10}{|c|}{ Tipos de Objetos } \\
\hline & & \multicolumn{2}{|c|}{ Al } & \multicolumn{2}{|c|}{ SUE } & \multicolumn{2}{|c|}{ DA } & \multicolumn{2}{|c|}{ AF } & \multicolumn{2}{|c|}{ ASM } \\
\hline & & C & E & C & E & C & E & C & E & C & $\mathbf{E}$ \\
\hline \multirow[t]{2}{*}{ Jogos de Papéis } & FCG & - & - & 2 & - & 3 & 1 & - & - & - & - \\
\hline & IPA & - & - & 2 & 4 & 3 & 3 & - & 1 & 1 & 4 \\
\hline \multirow{4}{*}{$\begin{array}{l}\text { Exploratórias com } \\
\text { Objetos }\end{array}$} & OC & 1 & - & - & 2 & - & 1 & 1 & 2 & 1 & 2 \\
\hline & OA & - & - & 1 & - & - & - & - & - & - & - \\
\hline & $\mathrm{N}$ & - & - & 1 & 2 & - & - & - & - & - & 1 \\
\hline & A & 1 & 1 & - & - & - & - & - & - & - & - \\
\hline Total & & 2 & 1 & 6 & 8 & 6 & 5 & 1 & 3 & 2 & 7 \\
\hline
\end{tabular}

4 Legenda: Tipos de Brincadeiras: FCG: Faz-de-Conta Genérico; IPA: Imitação de Papéis Adultos; OC: Orientado para a Criança; OA: Orientado para o Adulto; N: Naturais; A: Acadêmicos - Tipos de Objetos: AI: Atividades Intelectuais; SUE: Sem Uso Específico; DA: Desenvolvimento Afetivo; AF: Atividades Físicas; ASM: Atividades Sensório-Motoras de objetos para atividades físicas e para atividades sensóriomotoras apresenta freqüência absoluta mais alta no grupo masculino do que no feminino. Os meninos costumam usar estes dois tipos de objetos no seu faz-de-conta genérico, ao contrário das meninas.

A comparação entre essas duas tabelas demonstra também que, no contexto da escola, meninos não utilizam os objetos para o desenvolvimento afetivo em nenhuma de suas brincadeiras, enquanto as meninas não exibem brincadeiras exploratórias orientadas para o adulto. Observa-se ainda que meninos utilizam com freqüência absoluta mais alta objetos para atividades físicas, porém não há diferenças em relação aos sensório-motores; nestes a diferença se dá nos objetos usados.

Analisando-se estas tabelas pode-se perceber que nas atividades de brincar observadas, existem algumas diferenças nos tipos de objetos utilizados pelas crianças-foco em suas brincadeiras bem como na distribuição destes objetos em cada tipo de brincadeira. Estas diferenças ocorrem em dois níveis: contexto e gênero, pois, meninos e meninas escolhem objetos distintos para brincar num mesmo contexto; e os tipos de objetos utilizados pelas meninas ou pelos meninos em cada brincadeira diferem conforme o contexto. Por exemplo, em termos de gênero pode-se notar que no contexto de casa, meninos utilizam para suas brincadeiras objetos para o desenvolvimento afetivo como: aviões, binóculos, espadas, capacetes, heróis, postos de gasolina e ferrorama; por sua vez, as meninas usam materiais úteis para a construção de suas casinhas: como bonecas, panelinhas, paninhos, maquilagens e mamadeirinhas.

A observação das tabelas 3 e 4 demostra que também ocorrem diferenças em termos de gênero e de contexto nos temas desenvolvidos pelas crianças em suas brincadeiras de faz-de-conta. Meninos e meninas criam temas distintos para

Tabela 3. Quantidade de meninos de acordo com os temas das brincadeiras de jogos de papéis nos contextos de casa $(\mathrm{C})$ e da escola $(\mathrm{E})^{5}$

\begin{tabular}{lcccccccccccc}
\hline & \multicolumn{10}{c}{ Tipos de Temas } \\
\cline { 2 - 12 } Tipos de Brincadeiras & \multicolumn{1}{c}{ TD } & \multicolumn{1}{c}{ RF } & AC & & F & & \multicolumn{1}{c}{ SG } \\
\cline { 2 - 12 } & & C & E & C & E & C & E & C & E & C & E \\
\hline Jogos de Papéis & FCG & - & - & - & - & 2 & 1 & 2 & 1 & 3 & - \\
& IPA & - & - & - & 2 & - & 3 & - & - & - & - \\
\hline Total & & 0 & 0 & 0 & 2 & 2 & 4 & 2 & 1 & 3 & 0 \\
\hline
\end{tabular}

Tabela 4. Quantidade de meninas de acordo com os temas das brincadeiras de jogos de papéis nos contextos de casa $(C)$ e da escola $(E)^{5}$

\begin{tabular}{lcccccccccccc}
\hline & \multicolumn{10}{c}{ Tipos de Temas } \\
\cline { 2 - 12 } Tipos de Brincadeiras & \multicolumn{1}{c}{ TD } & \multicolumn{1}{c}{ RF } & AC & \multicolumn{1}{c}{ F } & & \multicolumn{2}{c}{ SG } \\
\cline { 2 - 13 } & & C & E & C & E & C & E & C & E & C & E \\
\hline Jogos de Papéis & FCG & 2 & 1 & 1 & - & 3 & 1 & - & - & - & - \\
& IPA & 2 & 3 & 1 & 2 & 2 & 1 & - & 1 & - & - \\
\hline Total & & 4 & 4 & 2 & 2 & 5 & 2 & 0 & 1 & 0 & 0 \\
\hline
\end{tabular}

5 Legendas: Tipos de Temas: TD: Tarefas Domésticas; RF: Relações Familiares e Extra-Familiares; AC: Atividades Cotidianas; F: Fantásticos; SG: Serviços Gerais 
o seu brincar imaginativo nos contextos de casa e da escola. Por exemplo, no contexto de casa, meninos não brincam de imitação de papéis adultos e os temas de seu faz-de-conta genérico centram-se em atividades cotidianas, temas fantásticos e serviços gerais. As meninas, por sua vez, desenvolvem temas em seu faz-de-conta genérico e imitação de papéis adultos relacionados a tarefas domésticas, relações familiares e extra-familiares e atividades cotidianas. No contexto da escola, meninos constroem temas ligados a atividades cotidianas e temas fantásticos, no faz-de-conta genérico; meninas, nesta mesma categoria, criam temas de tarefas domésticas e atividades cotidianas. Na imitação de papéis adultos, as meninas apresentam temas como tarefas domésticas, relações familiares e extra-familiares, atividades cotidianas e temas fantásticos; os meninos referem-se a atividades cotidianas e a relações familiares e extra-familiares. $\mathrm{O}$ conteúdo do faz-de-conta genérico apresenta discussões sobre família e atribuições de tarefas domésticas, porém meninos ocupam papéis masculinos (pai, filho) e meninas, femininos (mãe, empregada, filha, vizinha). Na imitação de papéis adultos, tema atividades cotidianas, meninos referemse a atividades mais amplas (compra e venda de produtos, trocas de dinheiro) do que as meninas, que relacionam atividades mais circunscritas (aniversários, visitas às vizinhas).

A forma como se distribuem as categorias tipos de objetos e de temas nas respectivas brincadeiras demonstra que as oportunidades oferecidas nos dois contextos, bem como os objetos disponíveis em cada um deles e as regras de conduta consideradas desejáveis são diferentes em casa e na escola. Estas diferenças também aparecem em termos de gênero, pois meninos e meninas organizam e estruturam suas brincadeiras de maneira distinta. Tendo em vista que os sistemas de significado cultural das mães e da professora são diferentes e, como aponta Valsiner (1989), a atividade de brincar da criança toma lugar em ambientes que estruturados fisicamente de acordo com os sistemas de significado cultural do grupo ao qual a criança pertence, estas diferenças são explicáveis e esperadas. Porém, como coloca este mesmo autor, o significado social do brincar é co-construído pela criança em sua interação com o ambiente e com os outros parceiros, processo no qual ela ressignifica as crenças e os valores que lhe são transmitidos, redefinindo os papéis sexuais, por exemplo. Este autor enfatiza que as crianças gradualmente constroem um compreender particular dos papéis sexuais. Esta construção a criança faz internamente e muitas vezes difere dos significados externos, frutos do grupo social ao qual ela pertence.

Scott (1990) aponta que o gênero refere-se à criação inteiramente social de idéias sobre os papéis adequados aos homens e às mulheres. É uma maneira de se referir às origens exclusivamente sociais das identidades subjetivas dos homens e das mulheres. O gênero é, segundo esta definição, uma categoria social imposta sobre um corpo sexuado e um dos primeiros modos de dar significado às relações de poder. Este processo de construção de significados está, segundo Louro (1990), estreitamente ligado à vida cotidiana. Ele prepara desde muito cedo as meninas e os meninos para as funções e tarefas que deveriam exercer quando adultos, tarefas estas que especificam o universo doméstico como domínio exclusivamente feminino.

Já Oliveira (1996) refere que o faz-de-conta, por criar uma atmosfera de "como se", permite à criança a internalização de regras e de imagens, que são encaminhadas e modificadas através das interações da criança com seus companheiros. A forma como meninas tratam os meninos, e viceversa, não pode ser interpretada como se referindo a um estado interno do sujeito, mas como uma representação social presente na cultura destas crianças e expressa por seu discurso. Quando a criança usa as informações sobre o papel de cada gênero, construídas culturalmente, ela gradualmente constrói sua própria versão de identidade de gênero. Portanto, qual a definição sexual que a criança constrói acerca dos objetos que lhe estão disponíveis em seu meio social, durante a sua atividade de brincar?

\section{Terceira etapa: Microanálise das atividades de brincar de quatro crianças}

A terceira etapa caracterizou-se pela microanálise das atividades de brincar de quatro crianças, seguindo uma adaptação do procedimento adotado por Valsiner (1987). As crianças escolhidas para a microanálise de suas atividades de brincar são aquelas em que referências explícitas acerca das diferenças de gênero foram feitas pelas suas mães durante as entrevistas. Analisou-se os sistemas de desenvolvimento individual longitudinalmente, em interdependência com os contextos de suas existências. As atividades de brincar das crianças escolhidas foram observadas em todos os momentos em que estas crianças apareciam em cena na filmagem. As brincadeiras foram analisadas da seguinte maneira: 1) explicitou-se as informações gerais sobre a família da criança e, em específico, as crenças maternas acerca da atividade de brincar da criança-foco; 2) fez-se uma descrição detalhada das seqüências de eventos das atividades de brincar da criança em que a definição de papéis sexuais mostrou-se evidente, em ambos os contextos, casa e escola. Foram registrados o tempo cronológico em que estes episódios ocorreram e o comportamento da criança-foco e de todas as crianças que estavam envolvidas na mesma atividade da criança-foco, dentro do episódio microanalisado. A seguir, alguns episódios serão descritos a fim de exemplificar o processo de microanálise:

\section{Episódio 1: Casa}

(20'17'') V. (menina) coloca uma fofoletti deitada nos braços da Barbie. Em seguida, faz Barbie amamentar a fofoletti com uma mamadeirinha de plástico (20’45”).

\section{Episódio 2: Escola}

(6’47”) A. (menino) está sentado em cima de um pneu, conversando com um colega. Este lhe propõe: Vamo fazê comida? A. responde afirmativamente. O colega diz: Então, 
vamo fazê comida. e canta Uma casinha nós vamos formar... A. observa-o. O colega pega uma pá e leva até A., que pede: Dá uma aí meu? O colega atira a pá para A., que a pega no chão (7'13").

Estes dois episódios ilustram a construção de um cenário estereotipado como feminino (brincar de casinha). O primeiro episódio demarca a reprodução de uma tarefa tipificada como feminina pelo contexto em que a atividade ocorre, explicitando que algumas vezes as crianças dão sentido às suas atividades e aos objetos utilizados nelas de acordo com os significados coletivamente compartilhados. O segundo episódio, em contrapartida, demonstra que as crianças não costumam brincar somente com objetos e brincadeiras tipificadas como características de seu gênero. Estes meninos reconstruíram o significado desta atividade, que é coletivamente compartilhado, dando-lhe um novo sentido, através do qual é permitido aos meninos exercerem uma tarefa tipicamente feminina neste grupo cultural.

\section{Episódio 3: Escola}

(10'05', ) V. (menina) chega até dois colegas, que brincam de delegacia, e diz: Eu tô brincando, tá K. ? Um outro colega comenta com o K.: Ela era ladrona? V. responde: Eu era polícia. K. responde negativamente com a cabeça e confirma: Ela era ladrona. O outro colega reafirma: Ela era ladrona, sim. V. sai correndo e mais colegas saem correndo atrás dela, dois deles empurrando seus pneus. Ao pegá-la, um deles diz: Vamo prá delegacia, eu levo ela. E vão (10'36').

A brincadeira de delegacia (polícia-ladrão) é tipicamente masculina na concepção do grupo a que V. pertence. Ao ingressar na brincadeira, V. tenta ocupar um papel definido pelo grupo como masculino (policial) em uma brincadeira masculina. Seus pares de negociação, todos meninos, reagem negativamente a esta tentativa e reestabelecem as regras: "ela era ladrona." Ou seja, estipulam um personagem feminino a V., que concorda prontamente. Esta cena demonstra que meninos e meninas transitam entre os universos de brincadeiras estereotipadas como femininas ou masculinas. Porém, os personagens representados por uns e por outros obedecem às regras de gênero: meninas representando personagens femininos e meninos personagens masculinos. Assim, as crianças podem brincar em espaços e cenários estabelecidos pela sua cultura como típicos do outro gênero, porém representando personagens que seguem o estereótipo de seu gênero. Dessa forma, as crianças reorganizam seus espaços de brincar, criando novos cenários para suas brincadeiras. Inventam novas funções para os objetos, redefinindo assim os papéis sexuais dos mesmos e representando personagens cujos comportamentos são aceitáveis pelo grupo a que pertencem.

\section{Episódio 4: Casa}

(23'14') D. (menino) pega o boneco de borracha e coloca nele um revólver de plástico. Enquanto faz isso, grita: Polícia, olha a polícia... Todos em seus postos. Parem em seus postos. Coloca o boneco de pé, apoiado num carrinho que está no chão. Se esse carro não parar, podem atirar! Pega a estrutura que havia montado com os carros em cima e puxa-a pelo chão (32'36', ).

Os objetos manipulados por D. em suas brincadeiras nestes episódios são estereotipados como masculinos (carrinho, revólver de plástico) e indiferenciados (bonecos de borracha, palhaço de plástico, pato de plástico, peças de encaixar, cordão do iô-iô). Nos episódios, D. cria cenários tipicamente masculinos para as suas brincadeiras, inventando novas funções para seus objetos e redefinindo os papéis sexuais de objetos indiferenciados para masculinos. Os espaços de brincar são reelaborados de acordo com os objetivos individuais de D. e com as regras e normas estabelecidos pela sua cultura.

\section{Episódio 5: Casa}

(5'13', C. (menina) está no pátio da vizinha, juntamente com três amigas e seu irmão. C. está de pé com uma ripa de madeira na mão, da mesma forma que seus companheiros. C. aproveita a flexibilidade da ripa e bate no ombro do seu irmão. As suas amigas fazem o mesmo. O irmão reage batendo nelas com a ripa. Todos riem muito (10'28',).

C. utiliza, neste episódio, objetos tipificados como indiferenciados pelo grupo a que ela pertence. Porém, o uso que faz das ripas de madeira em sua brincadeira pode ser caracterizado como tipicamente masculino, pois lutas e brigas são determinadas pelo contexto sociocultural de C. como brincadeiras masculinas.

\section{Episódio 6: Casa}

(44'26') C. (menina) brinca de roda com suas amigas na sala de sua casa. Elas escutam o disco da Xuxa. Fazem uma roda e encontram as mãos no centro da roda. Uma delas diz: Tá agora dá uma voltinha. Elas soltam as mãos e caminham em círculos, fazendo movimentos circulares com as mãos. Elas vão e vêm em sentidos contrários. Nesse momento, o irmão de C. que assistia a tudo sentado no sofá, levanta-se e entra na roda, imitando as meninas. Uma delas diz: Não, não abre! As quatro meninas fecham a roda, excluindo o irmão de C., que retorna ao sofá (45'03', ').

Desfilar e brincar de roda são brincadeiras caracterizadas pela mãe de C. como femininas. C. brinca de desfile, criando um cenário propício para esta atividade, sem redefinir os papéis sexuais tipificados pelo contexto sociocultural a que $\mathrm{C}$. pertence. $\mathrm{O}$ mesmo ocorre no episódio 6 em que a tentativa do irmão de $\mathrm{C}$. de ingressar na brincadeira das meninas foi rejeitada. Ou seja, parece que elas também delimitaram para ele que brincar de roda pertence ao universo feminino. Este último episódio demonstra que nem sempre as tentativas ativas da criança em redefinir os papéis sexuais de determinadas brincadeiras, ou de participar em atividades que não são tipificadas como características do seu gênero, são bem aceitas ou permitidas. As próprias crianças estabelecem regras relativas aos papéis sexuais, determinando o que é ou não possível, em tempo e lugar definidos. 
A análise de todos os episódios microanalisados responde à questão formulada na segunda etapa deste estudo, a saber: qual a definição sexual que a criança constrói acerca dos objetos que lhe estão disponíveis em seu meio social, durante a sua atividade de brincar? Esta análise demonstra que a criança muitas vezes tipifica os objetos disponíveis para o seu brincar de formas muito parecidas com os papéis sexuais estereotipados por sua cultura. Outras vezes, ela redefine estes papéis sexuais, reelaborando os espaços de brincar, reconstruindo os cenários de suas brincadeiras e inventando novas funções para os objetos utilizados nestas brincadeiras. Esta redefinição dos papéis sexuais é dinâmica e temporal (Valsiner, 1989). Ou seja, um mesmo objeto e uma mesma brincadeira podem ser ressignificados pela criança, em diferentes momentos, como feminino, masculino ou indiferenciado.

Pode-se concluir então que o ato de brincar, como salienta Wertsch $(1991 ; 1995)$, é uma ação mediada pelo contexto sociocultural e que o significado construído pela criança acerca da função de determinados objetos e da sua participação em certas brincadeiras não é estático. Segundo Valsiner (1989), esta construção depende, de um lado, dos sistemas de significado coletivamente compartilhados pelo grupo a que a criança pertence. Ou seja, conforme as crenças e os valores dos adultos responsáveis por ela (independente de ser a mãe ou a professora), certos objetos são colocados a sua disposição, determinadas brincadeiras serão aceitas ou não, diferentes comportamentos serão desejáveis ou proibidos. De outro lado, existe a versão construída pela criança acerca destes padrões sociais, versão esta que é construída a partir dos referenciais transmitidos pelo grupo a que ela pertence, mas que são ressignificados no seu cotidiano, nas suas interações com os outros parceiros. A criança, então, reelabora seus espaços de brincar, recriando cenários e inventando novas funções para os objetos de tal forma que tenham sentido para ela, mas que sejam adequados às determinações sociais. Talvez assim, o ressignificar do que já está estabelecido pela cultura permita que novos significados sejam gradualmente construídos, ao longo das décadas.

Neste sentido é que ocorre a bi-direcionalidade da transmissão cultural, pois a atividade de brincar da criança é estruturada conforme os sistemas de significado cultural do grupo a que ela pertence. Mas, ao mesmo tempo, esta atividade é reorganizada no próprio ato de brincar da criança, de acordo com o sentido particular que ela atribui às suas ações, em interação com seus pares ou com os membros mais competentes de sua cultura. E nesse processo, tanto os significados coletivos quanto os sentidos pessoais são remodelados e redefinidos continuamente.

\section{Referências}

Berlyne, D. E. (1963). Motivacional problems raised by exploratory and epistemic behavior. Em S. Koch (Org.), Psychology: A study of science (pp. 284-364). NY: McGraw-Hill

Bruner, J. (1976). Nature and uses of immaturity. Em J. S. Bruner, A . Jolly \& K. Sylva (Orgs.), Play. Its role in development and evolution (pp. 28-64). (Originalmente publicado em 1972). Middlesex: Penguin Books.

Farver, J. \& Wimbarti, S. (1995). Indonesian children's play with their mothers and older sibblings. Child Development, 66, 14931503.

Freud, S. (1976). Escritores criativos e devaneio. Em J. Strachey (Org.), Edição Standard Brasileira das Obras Psicológicas Completas de Sigmund Freud (vol. 9, pp. 149-162). (J. Salomão, Trad.) Rio de Janeiro: Imago. (Originalmente publicado em 1908).

Gaskins, S. \& Goncu, A . (1992). Cultural variation in play. A challenge to Piaget and Vygotsky. The Quarterly Newsletter of the Laboratory of Comparative Human Cognition, 14 (2), 31-35.

Gralinski, J.H. \& Kopp, C.B. (1993). Everyday rules for behavior: Mother's requests to young children. Developmental Psychology, 29, 573-584.

Groos, K. (1976). The play of animals: Play and instinct. Em J.S. Bruner, A. Jolly \& K. Sylva (Orgs.), Play. Its role in development and evolution (pp. 65-67). (Originalmente publicado em 1896). Middlesex: Penguin Books.

Louro, G.L. (1990). Lembranças de velhas colonas italianas: trabalho, família e educação. Educação e Realidade, 15 (2), 3343.

Lucariello, J. (1995). Mind, culture, person: Elements in a Cultural Psychology. Human Development, 38, 2-18.

Michelet, A. (1992). A classificação de jogos e brinquedos. A classificação I.C.C.P. Em A. Friedman (Org.), O direito de brincar. A brinquedoteca. SP: Página Aberta Ltda.

Oliveira, Z. de M.R. de (1996). Interações infantis em creche e a construção de representações sociais de gênero. Em M.I. Pedrosa (Org.), Coletâneas da ANPEPP: Investigação da criança em interação social, 1 (4), 69-82. Recife: Editora Universitária da UFPE.

Packer, M. (1994). Cultural work on the kindergarten playground: Articulating the ground of play. Human Development, 37, 259276.

Pedrosa, M.I. (1996). A emergência de significados entre crianças nos anos iniciais de vida. Em M.I. Pedrosa (Org.), Coletâneas da ANPEPP: Investigação da criança em interação social, 1 (4), 49-67. Recife: Editora Universitária da UFPE.

Piaget, J. (1978). A formação do símbolo na criança: imitação, jogo e sonho. Imagem e representação. (A. Cabral \& C.M. Oiticica, Trads.). Rio de Janeiro: Zahar. (Originalmente publicado em 1945).

Schwartzman, H.B. (1978). Transformation: The anthropology of children's play. NY: Plenum Press.

Scott, J. (1990). Gênero: uma categoria útil de análise histórica. Educação e Realidade, 15 (2), 5-22.

Shweder, R.A. (1991). Ideas of polytheistic nature. Em R.A. Shweder (Org.) Thinking through cultures. Expeditions in Cultural Psychology (pp. 25-110). MA: Harvard University Press.

Tudge, J., Sidden, J. \& Putnam, S. (1990). The cultural ecology of young children. Coding manual. Manuscrito não publicado. Universidade de Carolina do Norte, Greensboro.

Tudge, J., Putnam, S. \& Sidden, J. (1993). Preschooler's activities in socio-cultural context. The Quarterly of the Laboratory of Comparative Human Cognition, 15 (2), 71-84. 
Valsiner, J. (1987). Cultural regulation of children's action at mealtimes and its development. Em J. Valsiner (Org.), Culture and the Development of Children's Action (pp. 187-224). NY: John Wiley \& Sons Ltd.

Valsiner, J. (1988). Ontogeny of co-contruction of culture within socially organized environmental settings. Em J. Valsiner (Org.), Child developmental within culturally structured environments, vol. 2 (pp. 283-297). New Jersey: Ablex Publishing Corporation.

Valsiner, J. (1989). Human development and culture. The social nature of personality and its study. Lexington Books.

Vygotsky, L. (1989). O papel do brinquedo no desenvolvimento. Em J.C. Netto, L.S. Barreto \& S.C. Afeche (Orgs.), A forma- ção social da mente, (pp. 105-118). (L.S.M. Barreto \& S.C. Afeche, Trads.). São Paulo: Martins Fontes. (Originalmente publicado em 1933).

Wertsch, J.V. (1991). Voices of the mind. A sociocultural approach to mediated action. MA: Havard University Press.

Wertsch, J.V. (1995). Sociocultural research in the copyright age. Culture \& Psychology, 1, 81-102.

Winegar, L.T. (1988). Children's emerging understanding of social events: Co-construction and social press. Em J. Valsiner (Org.), Child development within culturally structured environments, vol. 2 (pp. 3-27). New Jersey: Ablex Publishing Corporation.

\section{Subscriptions}

Send your order for Subscriptions to the Psicologia: Teoria e Pesquisa to:

Revista Psicologia: Teoria e Pesquisa

Secretaria de Divulgação

Universidade de Brasília - Instituto de Psicologia

70910-900 Brasília - DF

BRAZIL

Rate for individuals US $\$ 48$

Rate for institutions US\$ 75

Past single numbers:

US\$ 14 (individual subscriber)

US\$20 (institutional subscriber)

US\$24 (not individual subscriber)

US\$ 37 (not institutional subscriber) 